University of Nebraska - Lincoln

DigitalCommons@University of Nebraska - Lincoln

Center for Brain, Biology and Behavior: Papers \&

Publications

Brain, Biology and Behavior, Center for

$10-10-2013$

\title{
Sex differences in white matter development during adolescence: A DTI study
}

Yingying Wang

Cincinnati Children's Hospital \& University of Cincinnati, yingying.wang@unl.edu

Chris Adamson

The Royal Children's Hospital

Weihong Yuan

Cincinnati Children's Hospital

Mekibib Altaye

Cincinnati Children's Hospital

Anna W. Byars

Cincinnati Children's Hospital

See next page for additional authors

Follow this and additional works at: https://digitalcommons.unl.edu/cbbbpapers

Part of the Behavior and Behavior Mechanisms Commons, Nervous System Commons, Other Analytical, Diagnostic and Therapeutic Techniques and Equipment Commons, Other Neuroscience and Neurobiology Commons, Other Psychiatry and Psychology Commons, Rehabilitation and Therapy Commons, and the Sports Sciences Commons

Wang, Yingying; Adamson, Chris; Yuan, Weihong; Altaye, Mekibib; Byars, Anna W.; and Holland, Scott K., "Sex differences in white matter development during adolescence: A DTI study" (2013). Center for Brain, Biology and Behavior: Papers \& Publications. 51.

https://digitalcommons.unl.edu/cbbbpapers/51

This Article is brought to you for free and open access by the Brain, Biology and Behavior, Center for at DigitalCommons@University of Nebraska - Lincoln. It has been accepted for inclusion in Center for Brain, Biology and Behavior: Papers \& Publications by an authorized administrator of DigitalCommons@University of Nebraska - Lincoln. 


\section{Authors}

Yingying Wang, Chris Adamson, Weihong Yuan, Mekibib Altaye, Anna W. Byars, and Scott K. Holland 
Brain Res. 2012 October 10; 1478: 1-15. doi:10.1016/j.brainres.2012.08.038.

\title{
Sex differences in white matter development during adolescence: A DTI study
}

\author{
Yingying Wanga,d,e, ${ }^{*}$, Chris Adamson ${ }^{f}$, Weihong Yuan ${ }^{a, b}$, Mekibib Altaye $^{c}$, Akila Rajagopal $^{\mathrm{a}}$, \\ Anna W. Byars ${ }^{d}$, and Scott K. Holland ${ }^{a, b, e}$ \\ aPediatric Neuroimaging Research Consortium, Cincinnati Children's Hospital, Cincinnati, OH, \\ United States \\ bDepartment of Radiology, Cincinnati Children's Hospital, Cincinnati, $\mathrm{OH}$, United States \\ 'Department of Biostatistics and Epidemiology, Cincinnati Children's Hospital, Cincinnati, $\mathrm{OH}$, \\ United States \\ dDivision of Neurology, Cincinnati Children's Hospital, Cincinnati, OH, United States \\ eDepartment of Biomedical Engineering, University of Cincinnati, Cincinnati, $\mathrm{OH}$, United States \\ fDevelopmental and Functional Brain Imaging, Critical Care and Neurosciences, Murdoch \\ Children's Research Institute, The Royal Children's Hospital, VIC, Australia
}

\section{Abstract}

Adolescence is a complex transitional period in human development, composing physical maturation, cognitive and social behavioral changes. The objective of this study is to investigate sex differences in white matter development and the associations between intelligence and white matter microstructure in the adolescent brain using diffusion tensor imaging (DTI) and tract-based spatial statistics (TBSS). In a cohort of 16 typically-developing adolescents aged 13 to 17 years, longitudinal DTI data were recorded from each subject at two time points that were one year apart. We used TBSS to analyze the diffusion indices including fractional anisotropy (FA), mean diffusivity (MD), axial diffusivity (AD), and radial diffusivity (RD). Our results suggest that boys (13-18 years) continued to demonstrate white matter maturation, whereas girls appeared to reach mature levels earlier. In addition, we identified significant positive correlations between FA and full-scale intelligence quotient (IQ) in the right inferior fronto-occipital fasciculus when both sexes were looked at together. Only girls showed significant positive correlations between FA and verbal IQ in the left cortico-spinal tract and superior longitudinal fasciculus. The preliminary evidence presented in this study supports that boys and girls have different developmental trajectories in white matter microstructure.

\section{Keywords}

Adolescence; Diffusion tensor imaging; Sex differences; Tract based spatial statistics; White matter development 


\section{Introduction}

Adolescence is a complex transitional time period composed of physical maturation, cognitive development, emotional and social behavioral changes (Blakemore and Choudhury, 2006; Casey et al., 2008; Spear, 2000). During this period, adulthood begins to emerge, childhood is left behind, but the decline of adult aging has not yet begun (Arnett, 2000; Dahl, 2004). Meanwhile, the increased sexual dimorphism driven by pubertal maturation may be the underlying cause of cognitive and emotional developmental differences between boys and girls (Brizendine, 2006; Herting et al., 2012; Perrin et al., 2009). Evidence from early brain morphology studies has revealed greater total gray and white matter volumes in boys than girls (Giedd et al., 1997', 1999), and significant regional age-related increases in white matter volume of the left inferior frontal region in boys but not in girls (Blakemore and Choudhury, 2006), as well as significant sex by age interaction for gray and white matter volume (De Bellis et al., 2001). Clinical evidence has also demonstrated sex differences in adolescent brain-behavior relationships (Brizendine, 2006; Cohen et al., 1999; De Bellis et al., 1999; Stice et al., 2001). The early onset of puberty in girls has been associated with later onset of schizophrenia (Cohen et al., 1999). Adolescent boys with post-traumatic stress disorder have shown more evidence of adverse brain development than girls (De Bellis et al., 1999). Adolescent girls have been shown to be more vulnerable to disorders such as depression and anorexia (Stice et al., 2001). Thus, understanding sexual dimorphism in normal brain maturation is crucial to develop a better understanding of the mechanism underlying such neuropsychiatric disorders.

The advent of the diffusion tensor imaging (DTI) technique provides a new dimension for understanding sexual dimorphism in brain maturation. DTI non-invasively measures water diffusion within brain tissue, which reflects the organizational integrity of white matter architecture and characteristics of fiber bundles in vivo (Basser, 1997; Le Bihan, 1991; Paus, 2010). This technique provides quantitative measures including fractional anisotropy (FA) as a normalized scalar measure of the degree of diffusion anisotropy, mean diffusivity (MD) as the magnitude of diffusional motion, axial diffusivity (AD) as diffusion parallel to white matter tracts, and radial diffusivity (RD) as diffusion perpendicular to white matter tracts (Le Bihan et al., 2001). These measures have been widely used in various clinical applications as markers of pathological changes in axonal density and size, myelination, and fiber organization (Le Bihan et al., 2001; Levin et al., 2011; Metwalli et al., 2010; Nguyen et al., 2011; Yuan et al., 2007). DTI has also been shown as a valuable imaging technique in studying characteristics of normal development of white matter (Hermoye et al., 2006; Lenroot and Giedd, 2010; Mukherjee et al., 2002; Schmithorst and Yuan, 2010; Schneider et al., 2004). In recent years, an increasing number of studies have demonstrated age-related differences in FA and MD and evident sex differences in white matter development during adolescence using regions of interest (ROI) (Bonekamp et al., 2007; Schneider et al., 2004; Schneiderman et al., 2007), tractography (Clayden et al., 2012; Eluvathingal et al., 2007; Lebel et al., 2008; Lebel and Beaulieu, 2011), or voxel-wise (Barnea-Goraly et al., 2005; Bava et al., 2011; Schmithorst et al., 2002, 2008', 2009) based analyses. Based on these DTI studies, age-related changes in white matter microstructure have been well established and most consistently show linear increases in FA and decreases in MD with age in white matter during adolescence, whereas the results of sexual dimorphism and sex by age interaction in the white matter seem to be less coherent. Bonekamp et al. (2007) have reported there was no significant effect of sex by age interaction in FA and MD. However, some other studies (Asato et al., 2010; Clayden et al., 2012; Schmithorst et al., 2008) have demonstrated significant sex by age interaction in various white matter tracts.

Recent DTI studies also have raised the recognition of the important role of white matter in supporting neural circuits (Schmahmann et al., 2007; Schmithorst et al., 2002) and cognitive 
function (Clayden et al., 2012; Mabbott et al., 2006, 2009; Nagy et al., 2004; Schmithorst et al., 2005; Tamnes et al., 2010). Schmithorst et al. (2005) found a positive correlation between intelligence quotient (IQ) and FA in bilateral frontal and occipito-parietal regions, suggesting a positive relationship between white matter fiber organization with cognitive function. Clayden et al. (2012) also have demonstrated that FA and MD independently predict intelligence using a comprehensive data-driven approach based on principal components analysis. They found positive loading in the splenium and left-side inferior longitudinal and arcuate fasciculi.

In this study, we investigated sex differences in white matter development and the association between intelligence and white matter microstructure in the adolescent brain using DTI and a novel tract-based spatial statistics (TBSS) method. TBSS (Smith et al., 2006) performs automated analysis of white matter integrity using nonlinear registration method and projecting individual DTI data onto a common skeleton depicting the estimated bisecting surfaces of the major white matter tracts. The method combines the strength of both voxel-based and tractography based analyses, and overcomes the limitations of conventional methods including partial volume, spatial smoothing, and arbitrary thresholds (Smith and Nichols, 2009). TBSS has been successfully applied to clinical studies and shown to improve sensitivity for detecting white matter diffusion changes, even with relatively small sample size $(n<30)$ (Focke et al., 2008; Yeh et al., 2009). The development of normalization and alignment techniques for DTI data using TBSS could improve sensitivity for detecting developmental changes in white matter microstructure and its association with IQ or cognitive function. In the current literature about DTI studies, most of the results regarding sex differences in white matter development during adolescence are based on cross-sectional study designs. The existing longitudinal studies (Bava et al., 2010; Giorgio et al., 2010) do not focus on sexual dimorphism and sex by age interaction in white matter microstructure. A recent longitudinal tractography study with DTI data acquired at 1.5 T by Lebel and Beaulieu demonstrated sex differences in 103 healthy subjects aged 5-32 years focusing on 10 major white matter tracts (Lebel and Beaulieu, 2011). For each tract, diffusion indices were averaged across all voxels along the tract among all subjects. This type of semiautomated tractography method depending on the user defined seed points can be subjective and less sensitive to small regional changes. Whereas TBSS aligns all subjects' FA maps into a common space, creates a mean FA skeleton representing the centers of all tracts common to the group and then projects all subjects' FA data onto the mean FA tract skeleton fed into voxel-wise analysis, which results in the best yet alignments of DTI data from multiple subjects. Taking advantage of the improved sensitivity for longitudinal changes in white matter microstructure offered by using TBSS with high quality DTI data obtained at 3.0 T, we expected to be able to detect specific regional differences between boys and girls in a one year period of development during adolescence, even with a small cohort of subjects. We further demonstrate the power in longitudinal DTI data by examining the relationship of WM development with IQ separately in boys and the girls using TBSS. Based on our previous work examining sex differences in WM development, we hypothesized that separation of the sexes in this analysis would allow us identify relationships between WM and intelligence that would not be apparent in a combined analysis of boys and girls. The sensitivity provided by DTI data in a longitudinal cohort allows us to establish this hypothesis unequivocally in a relatively small same of children.

\section{Results}

The demographics of participants are presented in Table 1 and show no significant differences in age, FSIQ, VIQ, and PIQ between boys and girls. The mean follow-up time between the first and second DTI scan was 12 months with standard deviation of 22 days. 


\subsection{Global mean of diffusion indices in the TBSS skeleton}

For the global mean FA, we found significant sex by age interaction $(F 1,14]=9.04, p=$ 0.009 ). One subject, the youngest boy (age 13 at time 1), had a value of global mean FA that deviated from the linear regression curve fitted to the entire sample. We considered the influence of this outlier on the statistical analysis and found that without this data point, the sex by age interaction was still marginally significant. Due to this significant sex by age interaction, we then evaluated the effect of age for boys and girls separately. There was significant effect of age of the global mean FA in boys $(F[1,7]=13.41, p=0.008)$ but not in girls $(F 1,7]=0.04, p=0.853)$. For the global mean values of other DTI indices, there was significant effect of sex for $\mathrm{MD}(F[1,14]=7.36, p=0.017), \mathrm{AD}(F[1,14]=10.21, p=$ $0.007)$, and $\mathrm{RD}(F[1,14]=4.67, p=0.049)$. Girls showed significantly higher global mean value of $\mathrm{MD}, \mathrm{AD}$ and $\mathrm{RD}$ than boys. But there was no significant sex by age interaction for any of these three indices. The scatter plots of all the global mean values of diffusion indices in Fig. 1 show linear regression trend lines for the boys and the girls separately. Only the trend for FA with age in boys is significant, as indicated by the solid line in Fig. 1. The other trends for $\mathrm{MD}, \mathrm{AD}$, and $\mathrm{RD}$ with age are not significant, as indicated by the dashed lines in Fig. 1.

\subsection{Sex and age interaction}

Regions showing significant sex by age interactions based on the TBSS results are represented by color magenta superimposed on the mean FA skeleton in color green as shown in Fig. 2 and summarized in Table 2. For FA, five clusters of tract regions were all identified in the left hemisphere including corticospinal tract (CST), forceps minor, inferior longitudinal fasciculus (ILF), superior longitudinal fasciculus (SLF), and uncinate fasciculus (UF). There was no region showing significant sex by age interaction in the other indices $(\mathrm{MD}, \mathrm{AD}, \mathrm{RD})$.

\subsection{Sex difference}

Table 3 and Fig. 3 summarize the voxel-wise comparison between boys and girls using TBSS with age as a covariate of no interest (nuisance variable in the design matrix for the program "Randomise"). Boys showed significantly higher FA than girls in the bilateral CST and left SLF, while there was no cluster showing significantly higher FA in girls than boys. For MD, girls showed significantly higher value than boys in the left inferior frontooccipital fasciculus (IFOF), left anterior thalamic radiation (ATR), right forceps minor, bilateral CST and SLF. For AD, we identified several regions showing significantly higher values in girls than boys including frontal and temporal parts of the left ATR, bilateral CST, right IFOF, right SLF, and body of corpus callosum (bCC). For RD, we found girls showing significantly higher values than boys in the left ATR, left forceps minor, bilateral CST and SLF. In $\mathrm{MD}, \mathrm{AD}$, and $\mathrm{RD}$, we did not detect any regions showing significantly higher values in boys than girls.

\subsection{Age effect}

Table 4 and Fig. 4 summarize TBSS results of regions showing significant age effect. Data from boys and girls were evaluated separately for FA due to the significant sex by age interactions. The slopes fitted to data from girls were not significant based on voxel-wise TBSS results, while boys showed significant positive age slope in the left ATR, IFOF, ILF, SLF, and UF. For MD, significant negative correlations between MD and age were found in the bilateral cingulum (cingulate gyrus) (CGC), CST, IFOF, and SLF. For AD, significant negative correlations between $\mathrm{AD}$ and age were observed in the right hemisphere including cingulum (hippocampus) (CGH), CST, IFOF, ILF, SLF, and UF. For RD, there were 
significant decreases in RD with age in the left hemisphere covering ATR, IFOF, SLF, and UF.

\subsection{Longitudinal changes}

Table 5 and Fig. 5 summarize clusters showing significant one-year changes in each diffusion index. There were seven clusters showing significant longitudinal increases of FA in boys but not in girls. They are all in the left hemisphere including ATR, CGC, CST, IFOF, UF, and forceps minor. Both forceps major and minor tracts showed significant increases of AD in boys but not in girls. There was no cluster showing significant one-year changes in either MD or RD.

\subsection{Voxel-wise correlation with intelligence measures}

Table 6 and Fig. 6 summarize significant voxel-wise correlations between intelligence measures and diffusivity indices with age as covariate of no interest. Significant correlations were identified between FSIQ score and FA in the right IFOF when both sexes were looked at together. There were two clusters in which VIQ score showed significant correlation with FA. They were located in the left CST and the left SLF when both sexes were looked at together. When we examined correlations for boys and girls separately, we found that VIQ score showed significant correlation with FA in girls but not in boys. There was no significant correlation found between PIQ score and any diffusion index.

\section{Discussion}

In this study, we utilized TBSS, a novel method for group analysis of DTI data, to investigate sex differences in white matter development during adolescence and correlation between the diffusion characteristics in white matter microstructure and IQ. We also provided quantitative estimates of one-year change in diffusion indices and identified sex differences in white matter development over the time course of one year, which complement our cross-sectional findings of sex differences in the white matter developmental trajectory (Schmithorst et al., 2002', 2008).

\subsection{Global changes of diffusion characteristics in white matter}

Consistent with cross-sectional studies in literature (Barnea-Goraly et al., 2005; Bonekamp et al., 2007; Giorgio et al., 2010; Schmithorst et al., 2002), our results from TBSS have demonstrated increases in the global mean FA values for adolescents from 13 to 18 years of age (see Fig. 1). Increased global mean FA values may suggest more organized fiber bundles. Many studies have shown rapid changes in diffusion parameters from 0 to 5 years of age (Barnea-Goraly et al., 2005; Hermoye et al., 2006; Löbel et al., 2009; Mukherjee et al., 2002) and have suggested an exponential trend in FA increase during childhood with more changes from 0 to 8 years of age and plateauing by late adolescence to early adulthood (Lebel et al., 2008; Lebel and Beaulieu, 2011). Our results showed significant sex by age interaction in the global mean FA values and found significant increases of the global mean FA values in boys but not in girls from 13 to 18 years of age. This finding might suggest earlier white matter maturation in girls than in boys based on the differences in FA increases with age. Moreover, we identified significant sex differences in the global mean values of $\mathrm{MD}, \mathrm{AD}$ and $\mathrm{RD}$. It has been reported that $\mathrm{AD}$ may be more sensitive to differences in axonal diameter (Schwartz et al., 2005). Girls showed significantly higher global mean MD, $\mathrm{AD}$ and $\mathrm{RD}$ than boys, which suggested sex-related differences in axonal organization, axonal caliber, or myelination. We also observed that the individual changes between Time 1 and 2 are occasionally in the opposite direction of the general trend (see Fig. 1), which demonstrates the importance and strength of longitudinal study design because we can see trends in individuals which may differ from the trend in a cross-sectional cohort. With 
additional subjects or additional years of data we may be able to differentiate sub-groups of children with various trends, possibly correlating with neurocognitive differences.

\subsection{Regional changes of diffusion characteristics in white matter}

For FA, we found significant sex by age interaction in the left CST, forceps minor, ILF, SLF, and UF (see Fig. 2 and Table 2). When controlling for age, we found significant higher FA in boys than girls in the bilateral CST and left SLF (see Fig. 3 and Table 3), contrary to the results from Bava et al. (2011), but consistent with other studies (Asato et al., 2010; Clayden et al., 2012; Herting et al., 2012; Lebel and Beaulieu, 2011; Rametti et al., 2010). Bava et al. showed higher FA in girls than boys in bilateral CST. Given that their study participants were young adolescents from 12 to 14 years of age, it is not surprising that our results differ. It can be interpreted that white matter tracts of girls developed earlier in bilateral CST during 12-14 years of age, and boys developed later in these regions during 13-18 years of age. Among the 13- to 18- year-old children studied, we found FA increases with age in five clusters including frontal, parietal, and temporal regions but not in occipital regions (see Fig. 4 and Table 4), consistent with other studies indicating protracted increases in anterior white matter volume (Giedd et al., 1999; Lebel et al., 2008; Mabbott et al., 2009). In addition, we observed that the age slopes for girls were flat and not significantly different from zero, whereas the age slopes for boys were significantly bigger than zero in the left ATR, IFOF, ILF, SLF, and UF, which agrees with recent evidence about sex differences in white matter developmental trajectory (Asato et al., 2010; Clayden et al., 2012). These findings also suggest earlier white matter maturation in girls than in boys. Nevertheless, we found continuing maturation of white matter from 13 to 18 years of age, in agreement with other studies (Asato et al., 2010; Barnea-Goraly et al., 2005; Lebel et al., 2008; Schmithorst et al., 2002). Longitudinal differences in FA showed less extensive changes, including six small clusters reflecting significant one-year increases in FA values in boys but not in girls (see Fig. 5 and Table 5). The sex differences in developmental trajectory of white matter anisotropic diffusion suggest that, by adolescence, girls have developed earlier than boys in widespread brain regions, which has been suggested to be related to microstructural processes rather than increases in total white matter volume (Asato et al., 2010; De Bellis et al., 2001; Paus and Toro, 2009). However, Bava et al. (2010) found longitudinal increases of FA mostly in right hemisphere in 22 healthy adolescents from 16 to 21 years of age. Due to the differences in age group, statistical analysis, and image thresholding method, we are limited in comparing their findings directly with ours. Their one-year changes in FA values range from 0.03 to 0.05 , while our results in FA changes over the time course of a year range from 0.05 to 0.09 for boys. These results are more complementary to each other than disparate and could indicate that white matter development continues from 13 to 17 into 1621 years of age with less progressive annual changes in the latter period (16-21 years of age). The less dramatic FA changes with age in their findings could also be explained because they did not separate boys and girls.

For MD, there was no cluster showing significant sex by age interaction, but there were seven clusters including the right forceps minor, left ATR, left IFOF, bilateral CST and SLF presenting significant sex differences (see Fig. 3 and Table 3), and eight clusters showing significant age-related decreases in the bilateral CGC, CST, IFOF, and SLF (see Fig. 4 and Table 4). We found girls had higher MD and lower FA in the bilateral frontal portion of the CST than boys, reflecting greater white matter density in bilateral CST for girl. This is consistent with a recent study in which a novel data driven approach was used to study the tract-based white matter maturation (Clayden et al., 2012). Our longitudinal analysis did not detect significant changes in MD for either sex over the time course of a year. This is contrary to the results from Bava et al. (2010) that identified significant longitudinal decreases of MD over the time course of a year in the cerebellar fibers, bilateral IFOF and 
SLF in children from 12 to 14 years of age. This may indicate that the one-year changes in MD are less rapid in our study group (13-18 years of age) than theirs (12-14 years of age).

For $\mathrm{AD}$, there was no cluster showing significant sex by age interactions. We identified six clusters including the left ATR, bCC, bilateral CST, right IFOF and SLF showing significant sex differences (see Fig. 3 and Table 3). Girls show significantly higher AD in the bilateral CST than boys do, consistent with another study (Bava et al., 2011). Connecting with our results that high VIQ score correlates with high FA in the left CST for girls but not for boys, higher $\mathrm{AD}$ in this region in girls than boys may indicate earlier development of verbal abilities in girls than boys. Moreover, girls show significantly higher AD in bCC than boys do. This result connects with previous fMRI findings of increased functional connectivity across the corpus callosum between the hemispheres for girls compared with boys performing a language task (Schmithorst and Holland, 2007).

For RD, there was no cluster showing significant sex by age interaction. We found six clusters showing significant sex differences in the left ATR, left forceps minor, bilateral CST and SLF (see Fig. 3 and Table 3), and four clusters in the left hemisphere showing significant age-related changes including ATR, IFOF, SLF, and UF (see Fig. 4 and Table 4). Connecting with our TBSS results of FA, the increases of FA are associated with decreases of RD in the left IFOF and SLF. Boys showed higher FA but lower RD in the left SLF. Animal studies have shown that higher values of FA and lower values of RD in mice reflect greater myelination (Song et al., 2005). Our findings can be interpreted that boys (13-18 years of age) may have greater myelination in the left SLF compared with girls, which is consistent with other studies (Herting et al., 2012).

\subsection{Correlations between intelligence measures and diffusion indices}

Consistent with our earlier cross-sectional study (Schmithorst et al., 2005), FSIQ was positively related to FA in the frontal part of the right IFOF when both sexes were looked at together, which indicates region-specific increases in FA may reflect efficient organization of white matter fiber bundles that lead to optimal cognitive performance (Schmithorst et al., 2005). However, we did not find negative correlations between FSIQ and FA in boys as reported in that study (Schmithorst et al., 2005), which may be due to different DTI analysis methods (TBSS was not used) and different study age group. In addition, there were two clusters including left CST and SLF showing significant correlation between VIQ and FA in girls but not in boys (see Table 6). This is an interesting finding which agrees with a recent longitudinal study (Ramsden et al., 2011). VIQ changes were related to the frontal portion of the left CST which controls motor speech, and the frontal portion of the left SLF which is a key language pathway that connects frontal lobe to temporal and parietal lobes and is responsible for information exchange between Broca and Wernicke's language regions (Paus et al., 1999).

\subsection{Future directions and conclusion}

Recent DTI methodological advances have improved our ability to discern sex differences in white matter microstructure and identify subtle changes in white matter tracts with longitudinal study design. Our study used the voxel-wise TBSS method for spatial normalization and analysis in order to minimize artifacts from imperfect spatial registration and avoid using arbitrary smoothing. Using this relatively conservative approach, the regions with significant age-related changes and sex differences found in the current study were limited compared to those found in other studies (Asato et al., 2010; Lebel et al., 2008; Schmithorst et al., 2008). Some discrepancies between longitudinal changes in this study and cross-sectional results may be explained by the relative small sample size $(n=16)$ and short time-span (1 year). However, it should be noted that with a longitudinal sample and 
TBSS methodology we have been able to identify sex-dependent trends in WM development in a cohort of 16 adolescents, that are consistent with and more specific than our previous work using a cross-sectional cohort of 106 children (Schmithorst et al., 2008). With equal numbers of scans from boys and girls obtained longitudinally over a one year span, we have been able to examine the interaction of IQ and WM development as a function of sex, identifying robust regional differences between the sexes. In future studies, as we continue to follow this longitudinal cohort through adolescence, we will develop a customized voxelwise algorithm for linear mixed-effects modeling for longitudinal study design. This approach will allow a more flexible covariance matrix structure, accounting for withinsubject error and missing data points, which will increase statistical power and enable more detailed examination of sexual dimorphism of WM growth curves during emerging adulthood.

In conclusion, developmental changes in white matter diffusion characteristics seen in this group of sixteen participants demonstrates that the longitudinal design, combined with TBSS methods, provides a powerful approach for investigating structural differences in the white matter that underlie developmental changes in brain function during adolescence. Our findings support the conclusions that the rates of white matter maturation differ between boys and girls at global level and the timing varies among different brain regions with frontal, parietal, and temporal regions maturing at a later age than the occipital region. This highlights the importance for neuroimaging studies to approach the analysis of data in developing populations with appropriate attention to the influence that sex may have on brain development. Boys (13-17 years) continue to demonstrate white matter maturation, whereas girls appear to reach mature levels earlier. In addition, we identified significant positive correlations between FA and FSIQ in the right IFOF when both sexes were looked at together, and positive correlations between FA and VIQ in the left CST and SLF in girls but not in boys. Moreover, this study indicates that sexual dimorphism in white matter maturation is important and should be taken into account in studies designed to examine white matter maturation.

\section{Experimental Procedures}

\subsection{Participants}

Twenty healthy, native English speaking adolescents were drawn from a longitudinal subgroup recruited from a larger cross-sectional sample of participants previously included in our fMRI studies of language development (Holland et al., 2007). Informed consent or assent was given by all parents and participants. This study was approved by the Institutional Review Board at Cincinnati Children's Hospital Medical Center. None of the participants had any neurological impairment or neurological trauma. Longitudinal diffusion image data were recorded at two time points which were one year apart from each other. Data from four participants were excluded due to poor quality diffusion images. Sixteen participants were included in this study with an average age of $15.30 \pm 1.24$ years old at the first time point, and $16.29 \pm 1.30$ at the second time point (mean $\pm \mathrm{SD}, 8$ boys and 8 girls).

\subsection{Neurocognitive testing}

Neurocognitive testing was administered under the supervision of one of the co-authors (AWB), a board certified neuropsychologist. All participants received the Wechsler Abbreviated Scale of Intelligence (WASI) (Wechsler, 1999) at time 2. The WASI is nationally standardized and yields verbal IQ (VIQ), performance IQ (PIQ), and full-scale IQ (FSIQ) scores, which has been regarded as a quick, reliable measure of intelligence and can be used to assess a broad age range from ages 6 through 89 years (Wechsler, 1999). 


\subsection{Image acquisition}

DTI data were acquired using a single-shot spin-echo, echo-planar imaging (SE-EPI) sequence on a Philips Achieva 3T MRI scanner with Dual Quasar gradients and transmit/ receive quadrature head coil (Philips Medical Systems, Best, The Netherlands). Acquisition parameters were: TR/TE $=12000 / 89 \mathrm{~ms}$, acquisition matrix $=92 \times 89$, field of view $=180 \times$ 180 (in-plane resolution $=2 \times 2 \mathrm{~mm}$ ), and slice thickness $=2 \mathrm{~mm}$ with no gap. Diffusion images were comprised of 32 diffusion weighted volumes with gradient encoding applied in 32 non-collinear directions and $b=1000 \mathrm{~s} / \mathrm{mm}^{2}$, and one non-diffusion weighted (T2weighted, $b=0 \mathrm{~s} / \mathrm{mm}^{2}$ ) reference image, denoted $b_{0}$.

\subsection{Image processing}

Images were pre-processed in the FSL software package (FMRIB software Library, FMRIB, Oxford, UK) (Smith et al., 2004) including correction for eddy current induced distortion and participant's head motion (Jenkinson and Smith, 2001) and generation of brain mask based on $b_{0}$ image (Smith, 2002). Then, pre-processed images were subjected to tensor decomposition for generating FA, MD, AD, and RD indices using FDT (FMRIB's Diffusion Toolbox) (Behrens et al., 2003). TBSS (Smith et al., 2006) was then used to prepare the individual diffusion maps for voxel-based group analysis by performing the following steps: all subjects' FA images were aligned into a template of averaged FA images (FMRIB-58) in Montreal Neurological Institute (MNI) space using a non-linear registration algorithm implemented in FNIRT (FMRIB's Non-linear Registration Tool) (Rueckert et al., 1999). After transformation into MNI space, a cohort mean FA image was created and thinned to generate a cohort mean FA skeleton of the white matter tracts. Each subject's aligned FA image was then projected onto the cohort mean FA skeleton by filling the cohort mean FA skeleton with FA values from the nearest relevant tract center, which was achieved by searching perpendicular to the local skeleton structure for maximum value. This second local coregistration step can alleviate the alignment problems. Voxel-wise statistical analysis across subjects on the skeleton space was carried out for voxels with FA $>0.2$ to include only major fiber bundles and exclude peripheral tracts with significant inter-subject variability. The $\mathrm{MD}, \mathrm{AD}$ and $\mathrm{RD}$ images were then transformed and projected in the same way onto the group white matter skeleton using the same registration parameters as the FA images.

\subsection{Statistical analysis}

Prior to the voxel-wise analysis, we calculated the global mean values of each DTI index (FA, MD, AD, and RD) from the whole-brain TBSS skeleton for each subject. Then, we modeledglobal mean values $=\beta_{0}+\beta_{1}(\operatorname{sex})+\beta_{2}($ age $)+\beta_{3}(\operatorname{sex} \times$ age $)+\varepsilon$, treating the two time points as repeated measures and performed mixed-effect model with restricted maximum likelihood (REML) ('PROC MIXED' procedure) using SAS 9.2 for Windows (SAS Institute Inc., Cary, NC, USA). If the sex by age interaction was not significant, we simplified the full model by removing the interaction term, leaving the reduced model: global mean values $=\beta_{0}+\beta_{1}(\operatorname{sex})+\beta_{2}($ age $)+\varepsilon$. If the sex by age interaction was significant, we modeled global mean values $=\beta_{0}+\beta_{1}$ (age $)+\varepsilon$ for boys and girls, respectively. The scatter plots were then generated using the ggplot package (Wickham, 2006) in the $R$ system (version 2.11.1 64 bit) (Ihaka and Gentleman, 1996).

For the voxel-wise analysis, a permutation program "Randomise" in FSL (Nichols and Holmes, 2002) was used to produce statistic maps with a standard general linear model (GLM) diffusion index values $=\beta_{0}+\beta_{1}(\operatorname{sex})+\beta_{2}(\mathrm{age})+\beta_{3}(\operatorname{sex} \times$ age $)+\varepsilon$ for each voxel. Since we have a between subject factor (sex) in addition to a within subject factor (age), the current version of "Randomise" cannot fit this type of data in a GLM. Thus, data from Time 1 and 2 for each subject were averaged and then fitted in a GLM. For voxels found to exhibit 
a significant sex by age interaction, we performed voxel-wise correlation analyses to determine the effect of age for boys and girls separately. The resulting contrast maps were enhanced via Threshold-Free Cluster Enhancement (TFCE) (Smith and Nichols, 2009) algorithm in FSL which can avoid the problem of selecting arbitrary smoothing kernel and thresholds for cluster size. All statistical results are corrected $p$-values at $p<0.05$ after controlling for family wise error rate. The center of gravity for each significant cluster was defined anatomically in MNI coordinates using the probabilistic John Hopkins University White Matter Atlas (Mori et al., 2008).

The longitudinal changes between time 2 and 1 were evaluated by using the difference between time 2 and time 1 data. Then, the program "Randomise" was used to detect significant non-zero mean clusters indicating significant one-year changes in all the diffusion indices. To further investigate this difference, DTI data from boys and girls were evaluated separately.

The voxel-wise correlation between diffusion indices (FA, MD, AD, and RD) and the intelligence measures (FSIQ, VIQ, and PIQ) was performed using the program "Randomise" while treating age as a covariate of no interest. To further investigate this correlation, DTI data from boys and girls were evaluated separately.

\section{Acknowledgments}

This study was supported in part by a grant from the U.S. National Institute of Health (NIH grant R01-HD38578, P.I. SK Holland). The study was also supported in part by the Victorian Government's Operational Infrastructure Support Program. The authors acknowledge the assistance of Ms. Amanda Huber, Ms. Sara Robertson and Ms. Julie Franks, for helping with recruitment and data collection, and Mr. Kendall O'Brien and Ms. Amanda Woods, for performing all the MRI scans.

\section{REFERENCES}

Arnett JJ. Emerging adulthood: a theory of development from the late teens through the twenties. Am. Psychol. 2000; 55:469-480. [PubMed: 10842426]

Asato MR, Terwilliger R, Woo J, Luna B. White matter development in adolescence: a DTI study. Cerebral. Cortex. 2010; 20:2122-2131. [PubMed: 20051363]

Barnea-Goraly N, Menon V, Eckert M, Tamm L, Bammer R, Karchemskiy A, Dant CC, Reiss AL. White matter development during childhood and adolescence: a cross-sectional diffusion tensor imaging study. Cerebral. Cortex. 2005; 15:1848-1854. [PubMed: 15758200]

Basser PJ. New histological and physiological stains derived from diffusion-tensor MR images. Ann. N.Y. Acad. Sci. 1997; 820:123-138. [PubMed: 9237452]

Bava S, Thayer R, Jacobus J, Ward M, Jernigan TL, Tapert SF. Longitudinal characterization of white matter maturation during adolescence. Brain Res. 2010; 1327:38-46. [PubMed: 20206151]

Bava S, Boucquey V, Goldenberg D, Thayer RE, Ward M, Jacobus J, Tapert SF. Sex differences in adolescent white matter architecture. Brain Res. 2011; 1375:41-48. [PubMed: 21172320]

Behrens TE, Woolrich MW, Jenkinson M, Johansen-Berg H, Nunes RG, Clare S, Matthews PM, Brady JM, Smith SM. Characterization and propagation of uncertainty in diffusion-weighted MR imaging. Magn. Reson. Med. 2003; 50:1077-1088. [PubMed: 14587019]

Blakemore SJ, Choudhury S. Development of the adolescent brain: implications for executive function and social cognition. J. Child. Psychol. Psychiatry. 2006; 47:296-312. [PubMed: 16492261]

Bonekamp D, Nagae LM, Degaonkar M, Matson M, Abdalla W, Barker PB, Mori S, Horská A. Diffusion tensor imaging in children and adolescents: reproducibility, hemispheric, and age-related differences. Neuroimage. 2007; 34:733-742. [PubMed: 17092743]

Brizendine, L. The Female Brain. New York: Broadway Books; 2006.

Casey B, Jones RM, Hare TA. The adolescent brain. Ann. N.Y. Acad. Sci. 2008; 1124:111-126. [PubMed: 18400927] 
Clayden JD, Jentschke S, Munoz M, Cooper JM, Chadwick MJ, Banks T, Clark CA, Vargha-Khadem F. Normative development of white matter tracts: similarities and differences in relation to age, gender, and intelligence. Cerebral. Cortex. 2012; 22:1738-1747. [PubMed: 21940703]

Cohen RZ, Seeman MV, Gotowiec A, Kopala L. Earlier puberty as a predictor of later onset of schizophrenia in women. Am. J. Psychiatry. 1999; 156:1059-1064. [PubMed: 10401452]

Dahl RE. Adolescent brain development: a period of vulnerabilities and opportunities. Keynote address. Ann. N.Y. Acad. Sci. 2004; 1021:1-22. [PubMed: 15251869]

De Bellis MD, Keshavan MS, Clark DB, Casey BJ, Giedd JN, Boring AM, Frustaci K, Ryan ND. A.E. bennett research award. Developmental traumatology. Part II: Brain development. Biol. Psychiatry. 1999; 45:1271-1284. [PubMed: 10349033]

De Bellis MD, Keshavan MS, Beers SR, Hall J, Frustaci K, Masalehdan A, Nol LJ, Boring AM. Sex differences in brain maturation during childhood and adolescence. Cerebral. Cortex. 2001; 11:552-557. [PubMed: 11375916]

Eluvathingal TJ, Hasan KM, Kramer L, Fletcher JM, Ewing-Cobbs L. Quantitative diffusion tensor tractography of association and projection fibers in normally developing children and adolescents. Cerebral. Cortex. 2007; 17:2760-2768. [PubMed: 17307759]

Focke NK, Yogarajah M, Bonelli SB, Bartlett PA, Symms MR, Duncan JS. Voxel-based diffusion tensor imaging in patients with mesial temporal lobe epilepsy and hippocampal sclerosis. Neuroimage. 2008; 40:728-737. [PubMed: 18261930]

Giedd JN, Castellanos FX, Rajapakse JC, Vaituzis AC, Rapoport JL. Sexual dimorphism of the developing human brain. Prog. Neuropsychopharmacol. Biol. Psychiatry. 1997; 21:1185-1201. [PubMed: 9460086]

Giedd JN, Blumenthal J, Jeffries NO, Castellanos FX, Liu H, Zijdenbos A, Paus T, Evans AC, Rapoport JL. Brain development during childhood and adolescence: a longitudinal MRI study. Nat. Neurosci. 1999; 2:861-863. [PubMed: 10491603]

Giorgio A, Watkins K, Chadwick M, James S, Winmill L, Douaud G, De Stefano N, Matthews P, Smith S, Johansen-Berg H. Longitudinal changes in grey and white matter during adolescence. Neuroimage. 2010; 49:94-103. [PubMed: 19679191]

Hermoye L, Saint-Martin C, Cosnard G, Lee SK, Kim J, Nassogne MC, Menten R, Clapuyt P, Donohue PK, Hua K, Wakana S, Jiang H, Van Zijl PC, Mori S. Pediatric diffusion tensor imaging: normal database and observation of the white matter maturation in early childhood. Neuroimage. 2006; 29:493-504. [PubMed: 16194615]

Herting MM, Maxwell EC, Irvine C, Nagel BJ. The impact of sex, puberty, and hormones on white matter microstructure in adolescents. Cerebral. Cortex. 2012; 22:1979-1992. [PubMed: 22002939]

Holland SK, Vannest J, Mecoli M, Jacola LM, Tillema JM, Karunanayaka PR, Schmithorst VJ, Yuan W, Plante E, Byars AW. Functional MRI of language lateralization during development in children. Int. J. Audiol. 2007; 46:533-551. [PubMed: 17828669]

Ihaka R, Gentleman R. a language for data analysis and graphics. J. Comput. Graph. Statist. 1996; 5:299-314.

Jenkinson M, Smith S. A global optimisation method for robust affine registration of brain images. Med. Image. Anal. 2001; 5:143-156. [PubMed: 11516708]

Le Bihan D. Molecular diffusion nuclear magnetic resonance imaging. Magn. Reson. Q. 1991; 7:1-30. [PubMed: 2043461]

Le Bihan D, Mangin JF, Poupon C, Clark CA, Pappata S, Molko N, Chabriat H. Diffusion tensor imaging: concepts and applications. J. Magn. Reson. Imaging. 2001; 13:534-546. [PubMed: 11276097]

Lebel C, Walker L, Leemans A, Phillips L, Beaulieu C. Microstructural maturation of the human brain from childhood to adulthood. Neuroimage. 2008; 40:1044-1055. [PubMed: 18295509]

Lebel C, Beaulieu C. Longitudinal development of human brain wiring continues from childhood into adulthood. J. Neurosci.: Off. J. Soc. Neurosci. 2011; 31:10937-10947.

Lenroot RK, Giedd JN. Sex differences in the adolescent brain. Brain Cogn. 2010; 72:46-55. [PubMed: 19913969] 
Levin HS, Wilde EA, Hanten G, Li X, Chu ZD, Vasquez AC, Cook L, Yallampalli R, Hunter JV. Mental state attributions and diffusion tensor imaging after traumatic brain injury in children. Dev Neuropsychol. 2011; 36:273-287. [PubMed: 21462007]

Löbel U, Sedlacik J, Güllmar D, Kaiser WA, Reichenbach JR, Mentzel HJ. Diffusion tensor imaging: the normal evolution of ADC, RA, FA, and eigenvalues studied in multiple anatomical regions of the brain. Neuroradiology. 2009; 51:253-263. [PubMed: 19132355]

Mabbott DJ, Noseworthy M, Bouffet E, Laughlin S, Rockel C. White matter growth as a mechanism of cognitive development in children. Neuroimage. 2006; 33:936-946. [PubMed: 16978884]

Mabbott DJ, Rovet J, Noseworthy MD, Smith ML, Rockel C. The relations between white matter and declarative memory in older children and adolescents. Brain Res. 2009; 1294:80-90. [PubMed: 19632208]

Metwalli NS, Benatar M, Nair G, Usher S, Hu X, Carew JD. Utility of axial and radial diffusivity from diffusion tensor MRI as markers of neurodegeneration in amyotrophic lateral sclerosis. Brain Res. 2010; 1348:156-164. [PubMed: 20513367]

Mori S, Oishi K, Jiang H, Jiang L, Li X, Akhter K, Hua K, Faria AV, Mahmood A, Woods R, Toga AW, Pike GB, Neto PR, Evans A, Zhang J, Huang H, Miller MI, Van Zijl P, Mazziotta J. Stereotaxic white matter atlas based on diffusion tensor imaging in an ICBM template. Neuroimage. 2008; 40:570-582. [PubMed: 18255316]

Mukherjee P, Miller JH, Shimony JS, Philip JV, Nehra D, Snyder AZ, Conturo TE, Neil JJ, Mckinstry RC. Diffusion-tensor MR imaging of gray and white matter development during normal human brain maturation. Am. J. Neuroradiol. 2002; 23:1445-1456. [PubMed: 12372731]

Nagy Z, Westerberg H, Klingberg T. Maturation of white matter is associated with the development of cognitive functions during childhood. J. Cogn. Neurosci. 2004; 16:1227-1233. [PubMed: 15453975]

Nguyen D, Vargas MI, Khaw N, Seeck M, Delavelle J, Lovblad KO, Haller S. Diffusion tensor imaging analysis with tract-based spatial statistics of the white matter abnormalities after epilepsy surgery. Epilepsy Res. 2011; 94:189-197.

Nichols TE, Holmes AP. Nonparametric permutation tests for functional neuroimaging: a primer with examples. Hum. Brain Mapp. 2002; 15:1-25. [PubMed: 11747097]

Paus T, Zijdenbos A, Worsley K, Collins DL, Blumenthal J, Giedd JN, Rapoport JL, Evans AC. Structural maturation of neural pathways in children and adolescents: in vivo study. Science. 1999; 283:1908-1911. [PubMed: 10082463]

Paus T, Toro R. Could sex differences in white matter be explained by g ratio? Front. Neuroanat. 2009; 3:14. [PubMed: 19753325]

Paus T. Growth of white matter in the adolescent brain: myelin or axon? Brain Cogn. 2010; 72:26-35. [PubMed: 19595493]

Perrin JS, Leonard G, Perron M, Pike GB, Pitiot A, Richer L, Veillette S, Pausova Z, Paus T. Sex differences in the growth of white matter during adolescence. Neuroimage. 2009; 45:1055-1066. [PubMed: 19349224]

Rametti G, Carrillo B, Gómez-Gil E, Junque C, Zubiarre-Elorza L, Segovia S, Gomez Á, Guillamon A. The microstructure of white matter in male to female transsexuals before cross-sex hormonal treatment. A DTI study. J. Psychiatr. Res. 2010; 45:949-954. [PubMed: 21195418]

Ramsden S, Richardson FM, Josse G, Thomas MS, Ellis C, Shakeshaft C, Seghier ML, Price CJ. Verbal and non-verbal intelligence changes in the teenage brain. Nature. 2011; 479:113-116. [PubMed: 22012265]

Rueckert D, Sonoda LI, Hayes C, Hill DLG, Leach MO, Hawkes DJ. Nonrigid registration using freeform deformations: application to breast MR images. IEEE Trans. Med. Imag. 1999; 18:712-721.

Schmahmann JD, Pandya DN, Wang R, Dai G, D'arceuil HE, De Crespigny AJ, Wedeen VJ. Association fibre pathways of the brain: parallel observations from diffusion spectrum imaging and autoradiography. Brain. 2007; 130:630-653. [PubMed: 17293361]

Schmithorst VJ, Wilke M, Dardzinski BJ, Holland SK. Correlation of white matter diffusivity and anisotropy with age during childhood and adolescence: a cross-sectional diffusion-tensor MR imaging study. Radiology. 2002; 222:212-218. [PubMed: 11756728] 
Schmithorst VJ, Wilke M, Dardzinski BJ, Holland SK. Cognitive functions correlate with white matter architecture in a normal pediatric population: a diffusion tensor MRI study. Hum. Brain Mapp. 2005; 26:139-147. [PubMed: 15858815]

Schmithorst VJ, Holland SK. Sex differences in the development of neuroanatomical functional connectivity underlying intelligence found using Bayesian connectivity analysis. Neuroimage. 2007; 35:406-419. [PubMed: 17223578]

Schmithorst VJ, Holland SK, Dardzinski BJ. Developmental differences in white matter architecture between boys and girls. Hum. Brain Mapp. 2008; 29:696-710. [PubMed: 17598163]

Schmithorst VJ. Developmental sex differences in the relation of neuroanatomical connectivity to intelligence. Intelligence. 2009; 37:164-173. [PubMed: 21297966]

Schmithorst VJ, Yuan W. White matter development during adolescence as shown by diffusion MRI. Brain Cogn. 2010; 72:16-25. [PubMed: 19628324]

Schneider JF, Il'yasov KA, Hennig J, Martin E. Fast quantitative diffusion-tensor imaging of cerebral white matter from the neonatal period to adolescence. Neuroradiology. 2004; 46:258-266. [PubMed: 14999435]

Schneiderman JS, Buchsbaum MS, Haznedar MM, Hazlett EA, Brickman AM, Shihabuddin L, Brand JG, Torosjan Y, Newmark RE, Tang C, Aronowitz J, Paul-Odouard R, Byne W, Hof PR. Diffusion tensor anisotropy in adolescents and adults. Neuropsychobiology. 2007; 55:96-111. [PubMed: 17587876]

Schwartz ED, Cooper ET, Fan Y, Jawad AF, Chin CL, Nissanov J, Hackney DB. MRI diffusion coefficients in spinal cord correlate with axon morphometry. Neuroreport. 2005; 16:73-76. [PubMed: 15618894]

Smith SM. Fast robust automated brain extraction. Hum. Brain Mapp. 2002; 17:143-155. [PubMed: 12391568]

Smith SM, Jenkinson M, Woolrich MW, Beckmann CF, Behrens TE, Johansen-Berg H, Bannister PR, De Luca M, Drobnjak I, Flitney DE, Niazy RK, Saunders J, Vickers J, Zhang Y, De Stefano N, Brady JM, Matthews PM. Advances in functional and structural MR image analysis and implementation as FSL. Neuroimage. 2004; 23(Suppl 1):S208-S219. [PubMed: 15501092]

Smith SM, Jenkinson M, Johansen-Berg H, Rueckert D, Nichols TE, Mackay CE, Watkins KE, Ciccarelli O, Cader MZ, Matthews PM, Behrens TEJ. Tract-based spatial statistics: voxelwise analysis of multi-subject diffusion data. Neuroimage. 2006; 31:1487-1505. [PubMed: 16624579]

Smith SM, Nichols TE. Threshold-free cluster enhancement: addressing problems of smoothing, threshold dependence and localisation in cluster inference. Neuroimage. 2009; 44:83-98. [PubMed: 18501637]

Song SK, Yoshino J, Le TQ, Lin SJ, Sun SW, Cross AH, Armstrong RC. Demyelination increases radial diffusivity in corpus callosum of mouse brain. Neuroimage. 2005; 26:132-140. [PubMed: 15862213]

Spear LP. The adolescent brain and age-related behavioral manifestations. Neurosci. Biobehav. Rev. 2000; 24:417-463. [PubMed: 10817843]

Stice E, Presnell K, Bearman SK. Relation of early menarche to depression, eating disorders, substance abuse, and comorbid psychopathology among adolescent girls. Dev. Psychol. 2001; 37:608-619. [PubMed: 11552757]

Tamnes CK, Ostby Y, Walhovd KB, Westlye LT, Due-Tonnessen P, Fjell AM. Intellectual abilities and white matter microstructure in development: a diffusion tensor imaging study. Hum. Brain Mapp. 2010; 31:1609-1625. [PubMed: 20162594]

Wechsler D. Wechsler abbreviated scale of intelligence. Psychol. Corp. 1999

Wickham H. ggplot: An implementation of the Grammar of Graphics. R. R package version 0.4. 0. 2006

Yeh PH, Simpson K, Durazzo TC, Gazdzinski S, Meyerhoff DJ. Tract-based spatial statistics (TBSS) of diffusion tensor imaging data in alcohol dependence: abnormalities of the motivational neurocircuitry. Psychiatry Res. 2009; 173:22-30. [PubMed: 19442492]

Yuan W, Holland SK, Schmithorst VJ, Walz NC, Cecil KM, Jones BV, Karunanayaka P, Michaud L, Wade SL. Diffusion tensor MR imaging reveals persistent white matter alteration after traumatic 
brain injury experienced during early childhood. AJNR Am. J. Neuroradiol. 2007; 28:1919-1925. [PubMed: 17905895] 

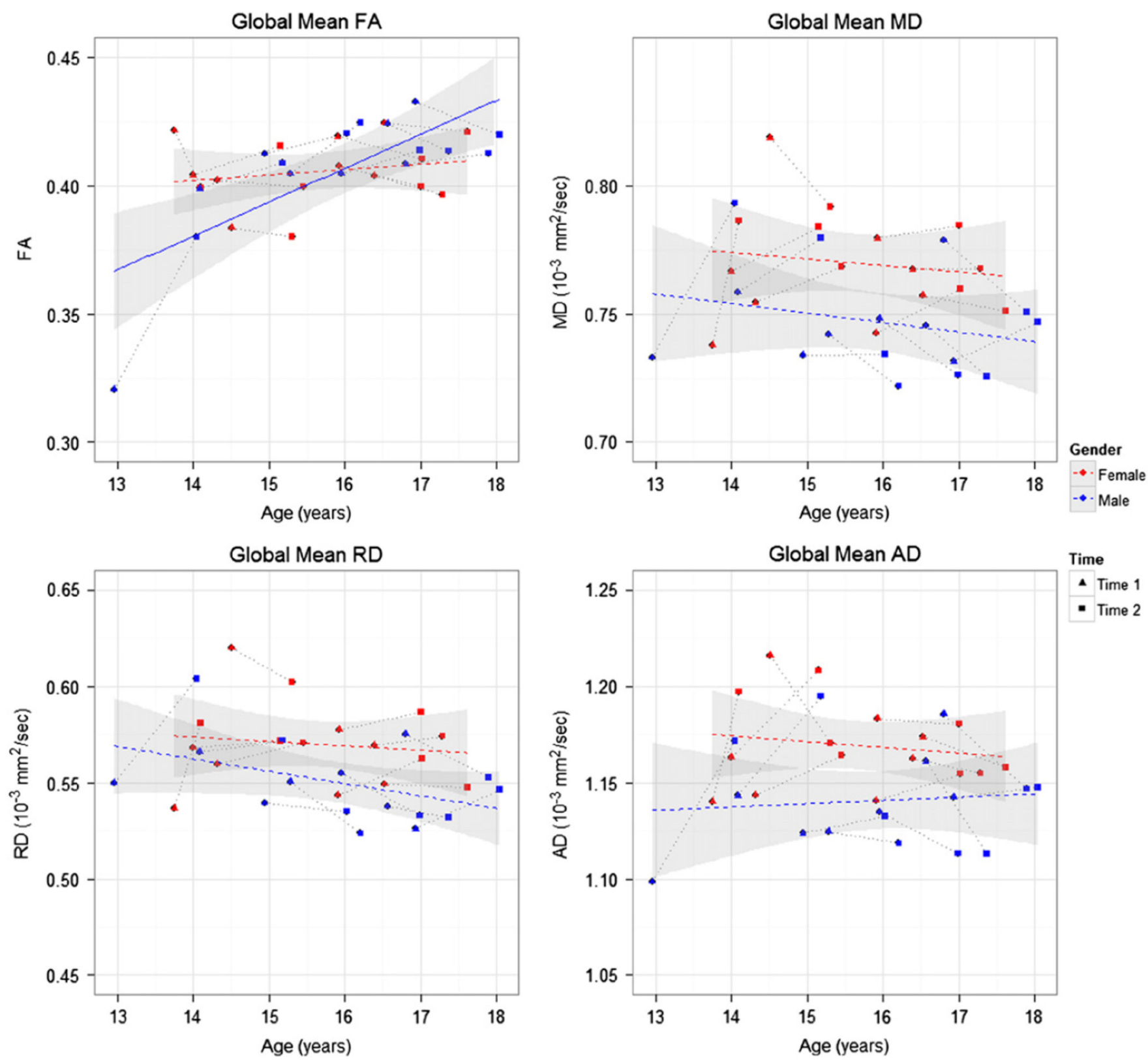

Fig. 1.

Scatter plots of the global mean values of each diffusion index calculated from the wholebrain TBSS skeleton, along with least squares regression lines for each sex. FA: fractional anisotropy; MD: mean diffusivity; AD: axial diffusivity; RD: radial diffusivity. Red symbols and lines represent girls and blue represents boys. Time point 1 and 2 are represented by triangles and circles, respectively, and are connected to each other by grey dotted lines. The standard errors are shown with a grey band around the regression line. The solid regression line denotes statistical significance, while the dashed regression lines indicate the trend without significance. 


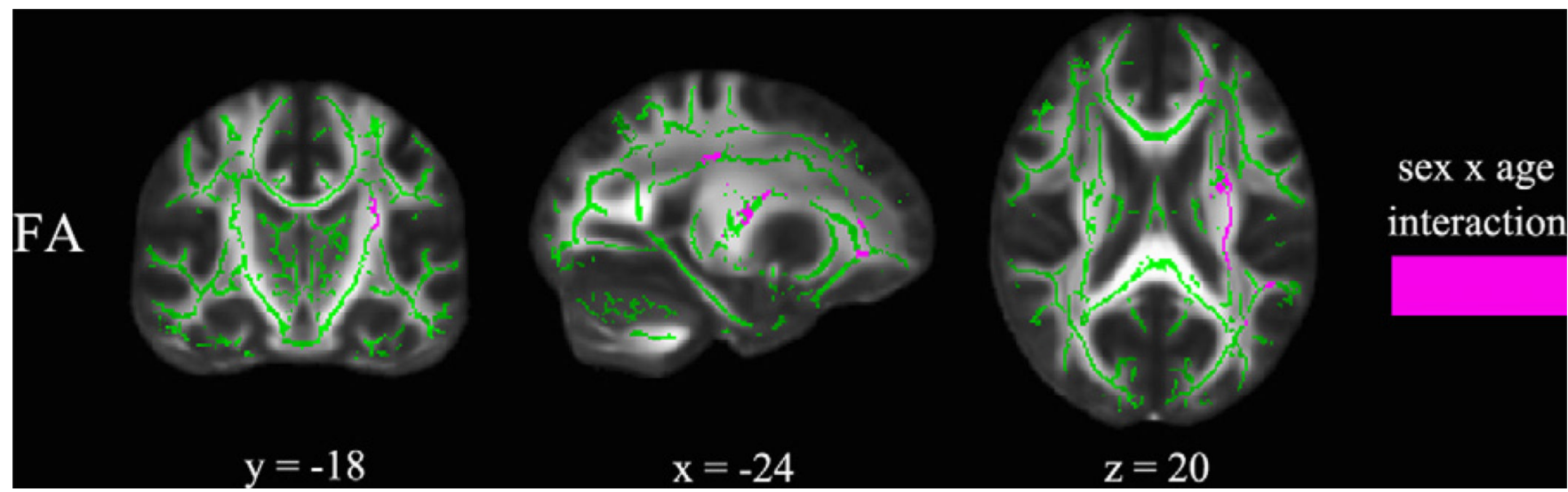

Fig. 2.

TBSS results of significant sex by age interactions ( $p<0.05$, corrected) for FA corresponding to Table 2 . The results from sex by age interactions are shown in magenta superimposed on the fiber skeleton (Green) and overlaid on the FMRIB FA template.

Images are in radiological convention. $x$ : right $\leftrightarrow$ left direction; $y$ : anterior $\leftrightarrow$ posterior direction; $Z$. superior $\leftrightarrow$ inferior direction. (For interpretation of the references to color in this figure legend, the reader is referred to the web version of this article.) 


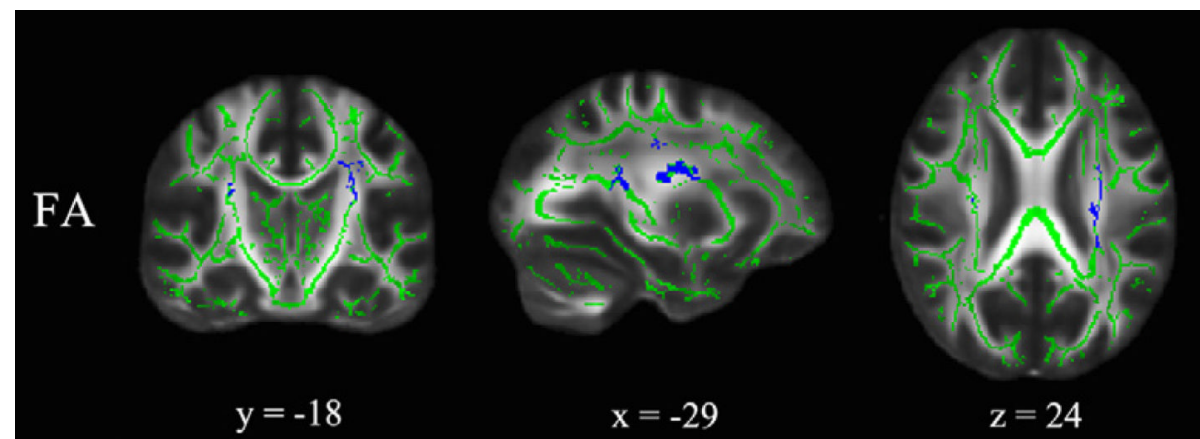

$y=-7$

$x=-28$

$\mathrm{Z}=20$
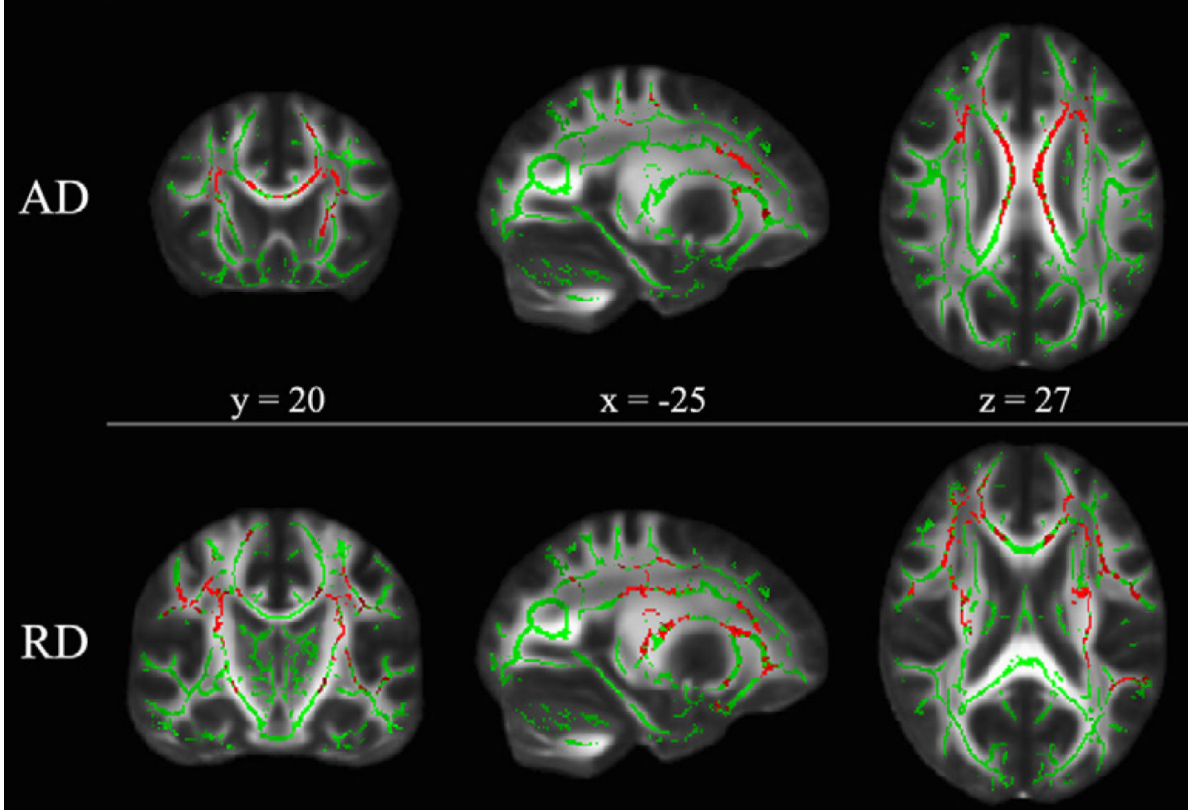

$y=-18$

$x=-25$

$\mathrm{z}=20$

Fig. 3.

TBSS results of significant sex effects ( $p<0.05$, corrected) in each diffusion index corresponding to Table 3 . The results from sex effect superimposed on the fiber skeleton (Green) and overlaid on the FMRIB FA template. Red represents the regions that girls show significant higher values than boys. Blue represents regions that boys show significant higher values than girls. Images are in radiological convention. $x$ : right $\leftrightarrow$ left direction; $y$ : anterior $\leftrightarrow$ posterior direction; $Z$. superior $\leftrightarrow$ inferior direction. 


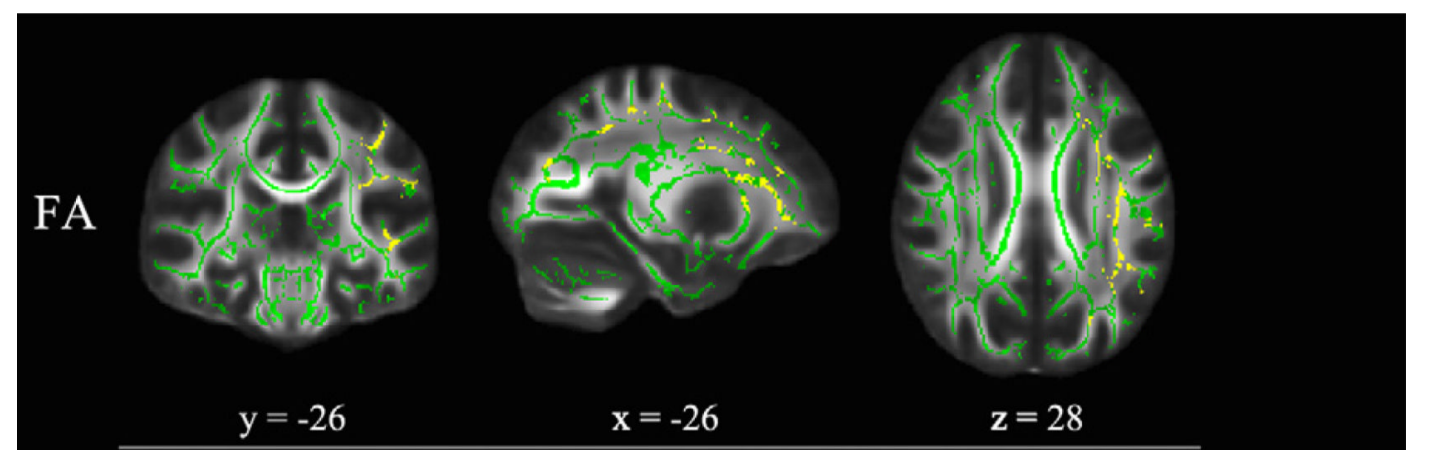

MD
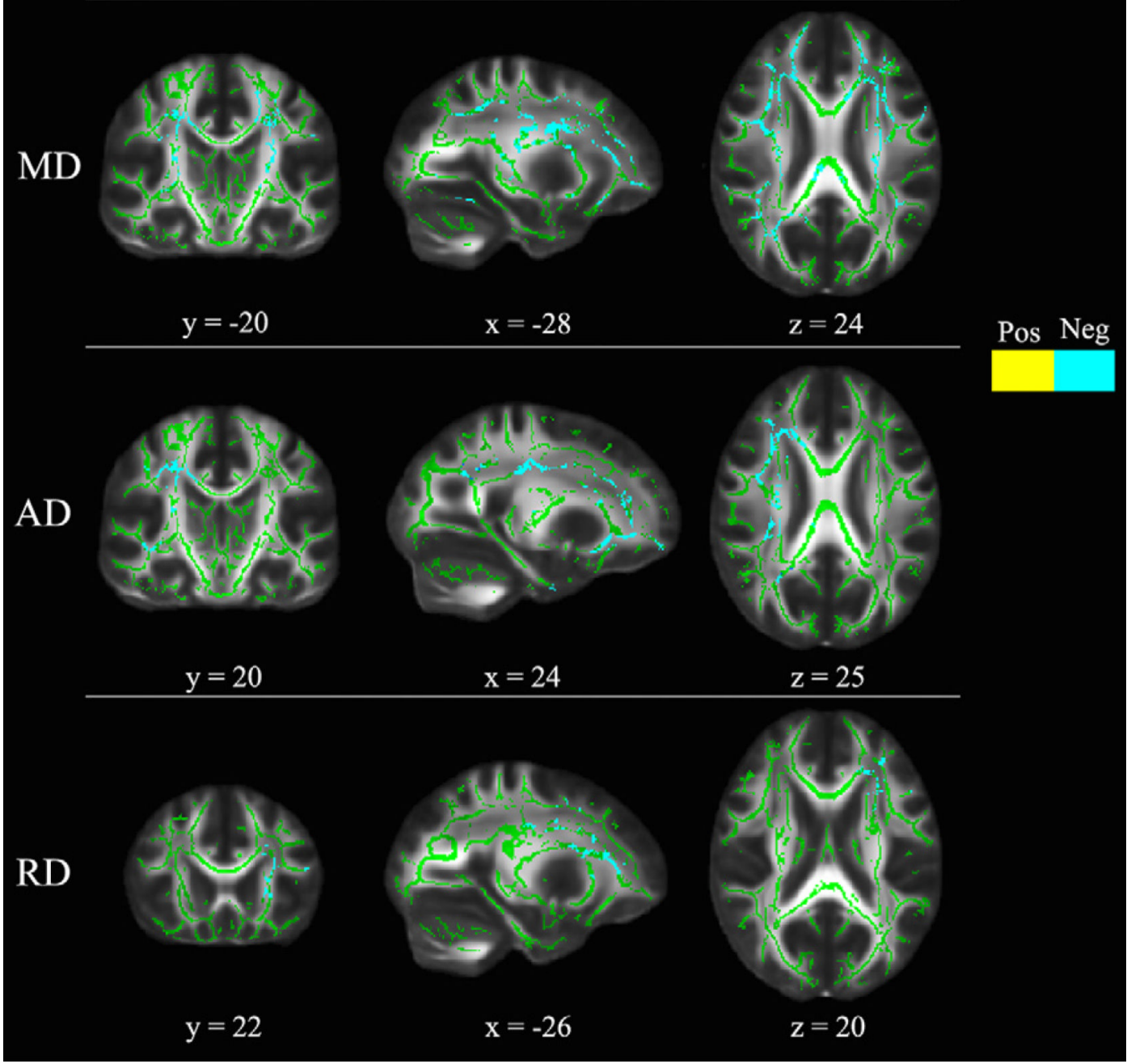

Fig. 4.

TBSS results of significant age effects ( $p<0.05$, corrected) in each diffusion index corresponding to Table 4 . The results from age effect are superimposed on the fiber skeleton (Green) and overlaid on the FMRIB FA template. Yellow represents increases with age and cyan represents decreases with age using data from both boys and girls. Note the age trend for FA was merely driven by data from boys. Images are in radiological convention. $x$ : right $\leftrightarrow$ left direction; $y$. anterior $\leftrightarrow$ posterior direction; $z$. superior $\leftrightarrow$ inferior direction. 

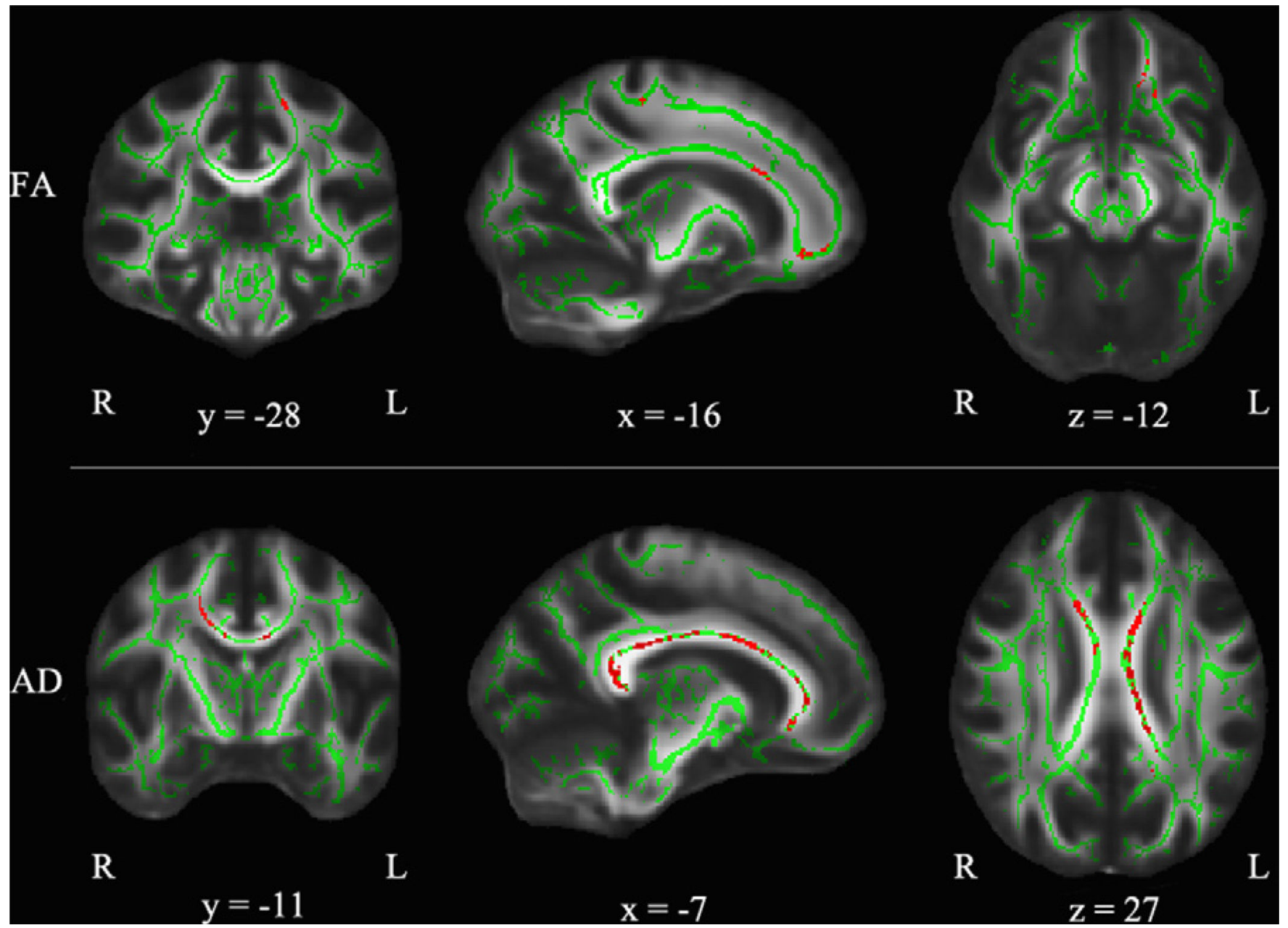

Fig. 5.

TBSS results of significant changes between time 2 and time 1 ( $p<0.05$, corrected) corresponding to Table 5 for boys. No regions were found with significant time dependence in girls. Results are superimposed on the fiber skeleton (Green) and overlaid on the FMRIB FA template. The color red represents increases from time 1 to 2 . Images are in radiological convention. $x$ : right $\leftrightarrow$ left direction; $y$ : anterior $\leftrightarrow$ posterior direction; $z$. superior $\leftrightarrow$ inferior direction. (For interpretation of the references to color in this figure legend, the reader is referred to the web version of this article.) 


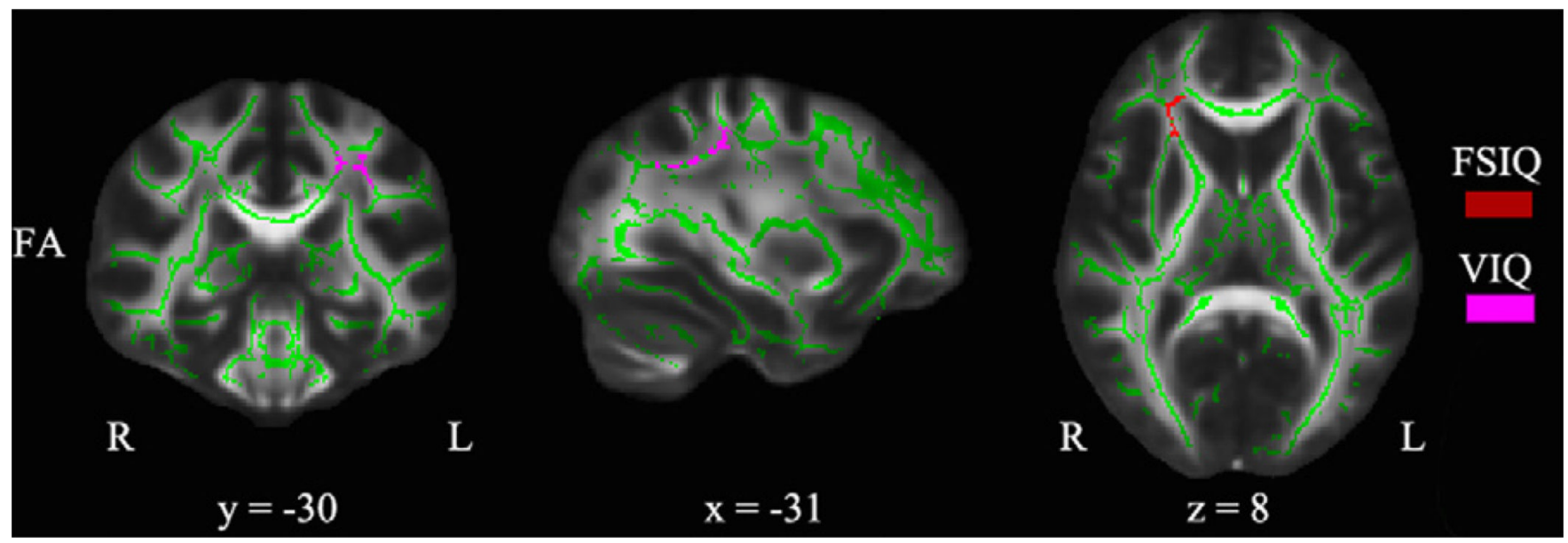

Fig. 6.

TBSS results of significant correlations between FA and intelligence measures $(p<0.05$, corrected) corresponding to Table 6 when both sexes were looked at together. Results are superimposed on the fiber skeleton (Green) and overlaid on the FMRIB FA template. The color red represents positive correlation between FA and FSIQ, and fuchsia represents positive correlation between FA and VIQ. Images are in radiological convention. $x$ : right $\leftrightarrow$ left direction; $y$. anterior $\leftrightarrow$ posterior direction; $z$. superior $\leftrightarrow$ inferior direction. (For interpretation of the references to color in this figure legend, the reader is referred to the web version of this article.) 


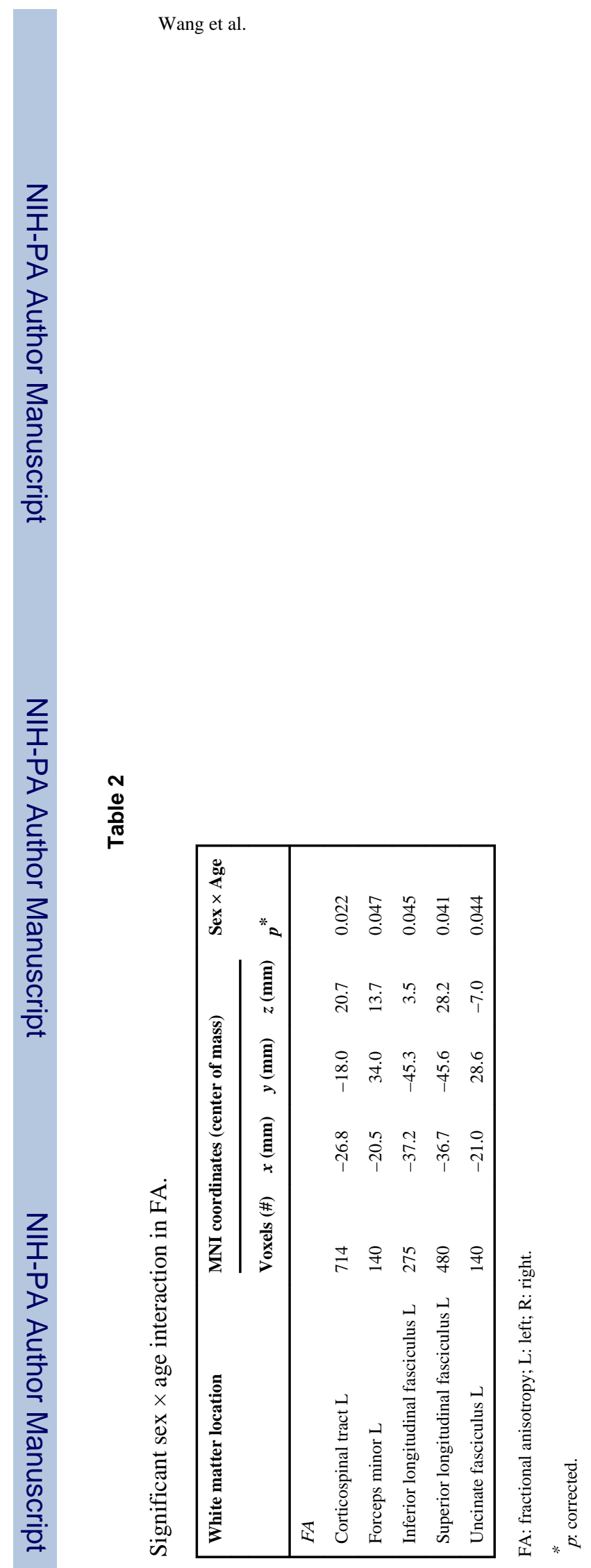

Brain Res. Author manuscript; available in PMC 2013 October 10. 


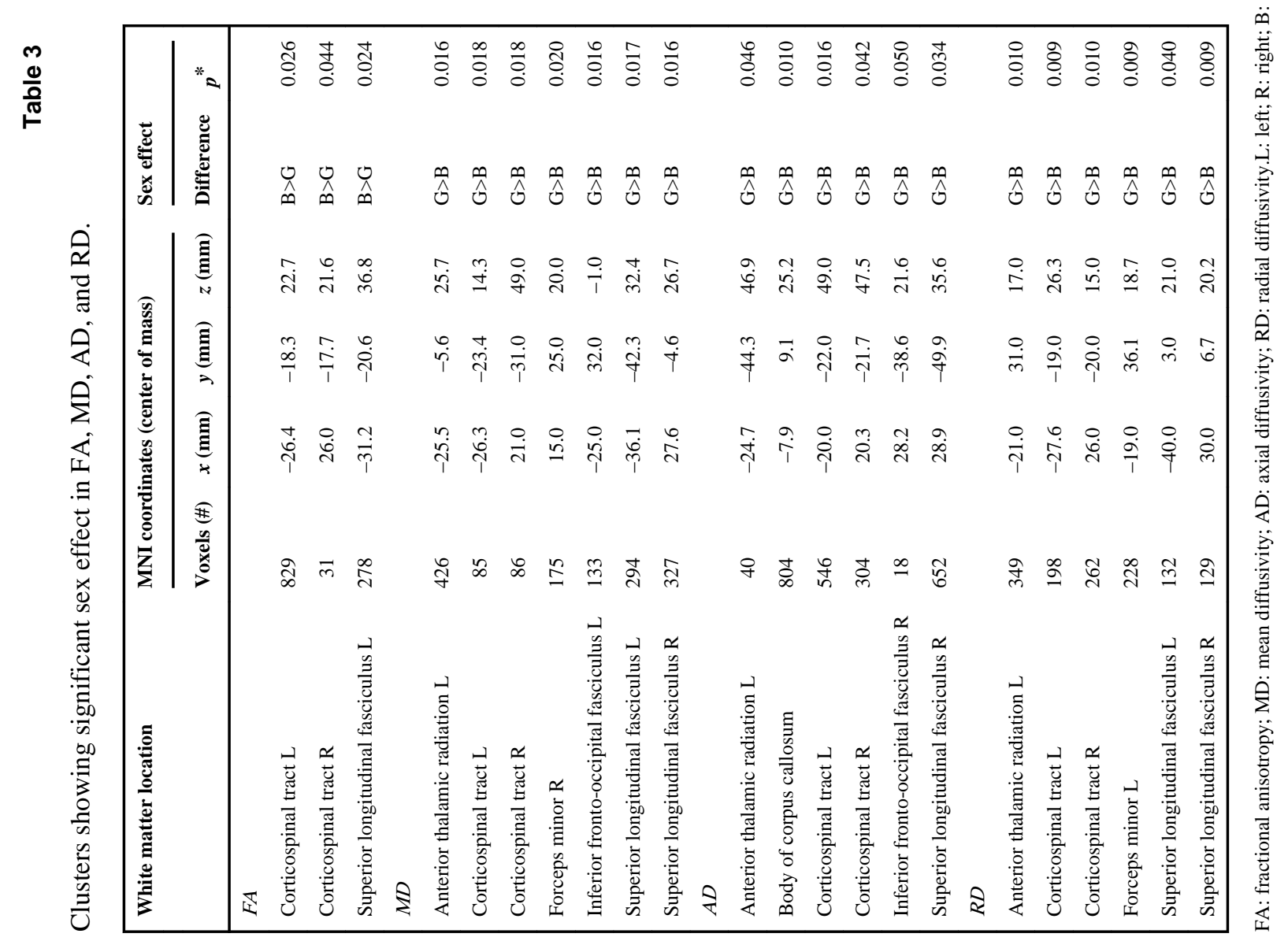




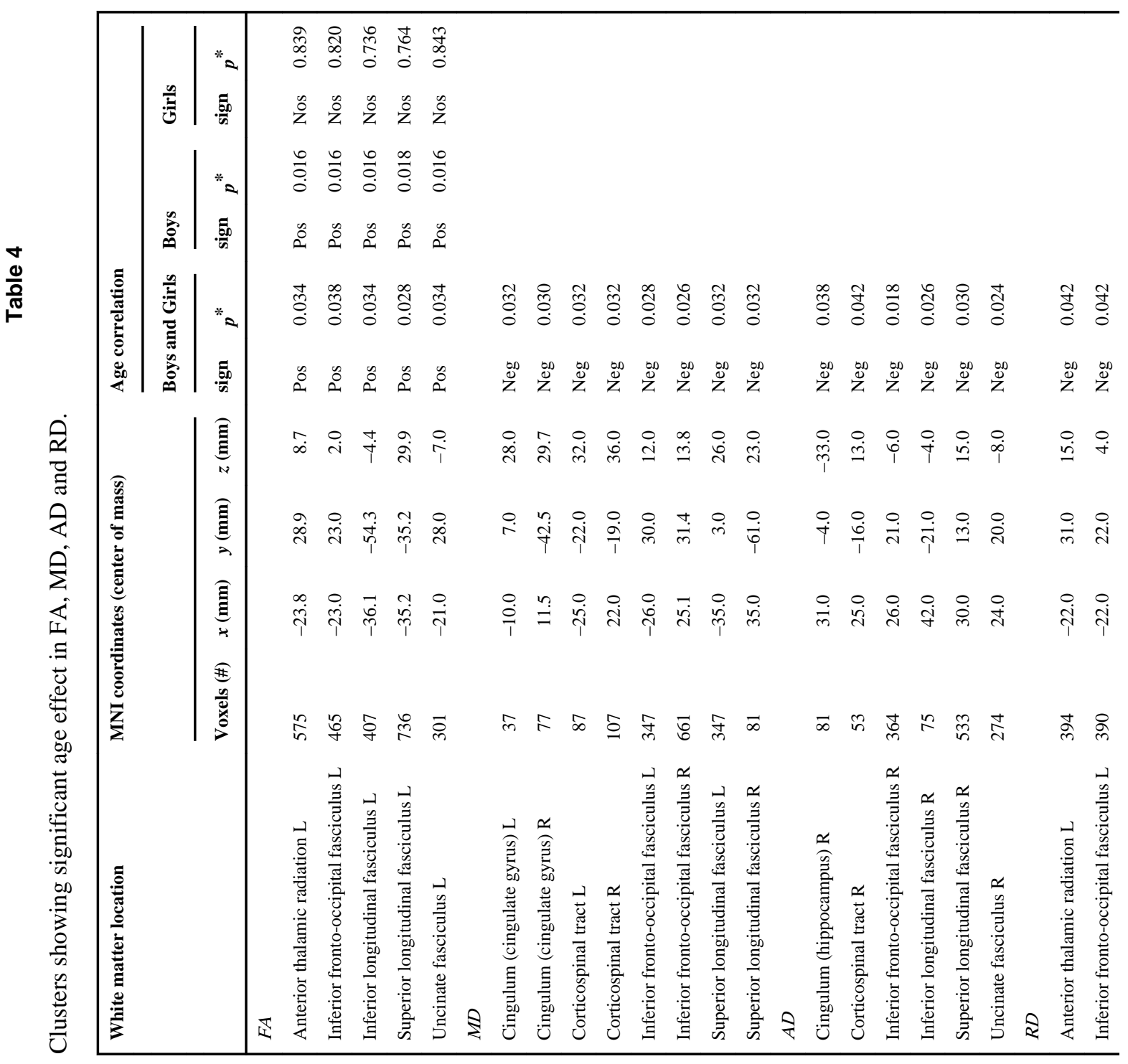

Brain Res. Author manuscript; available in PMC 2013 October 10. 


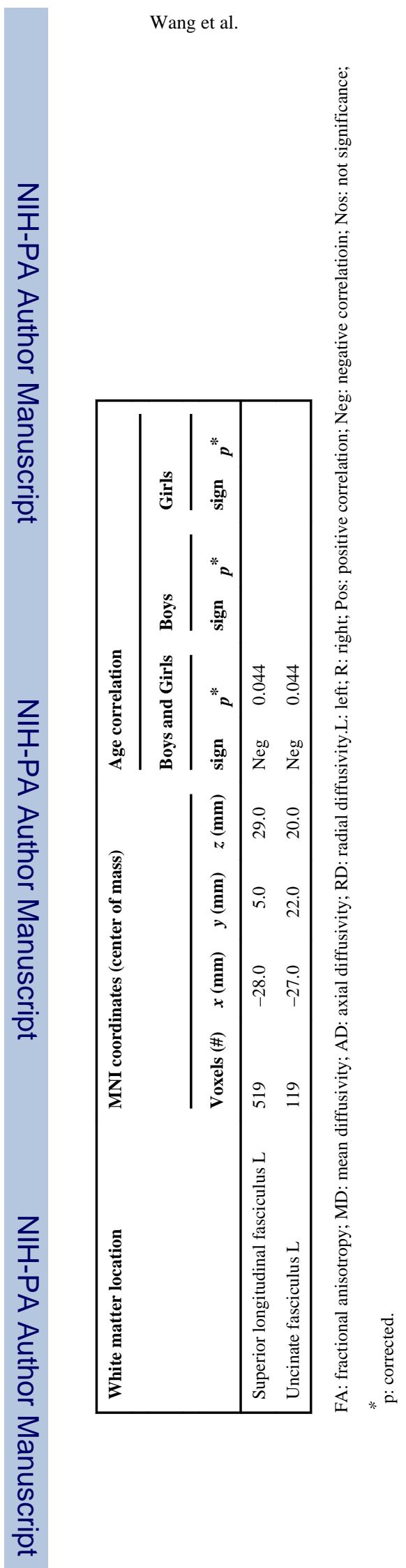

Brain Res. Author manuscript; available in PMC 2013 October 10. 


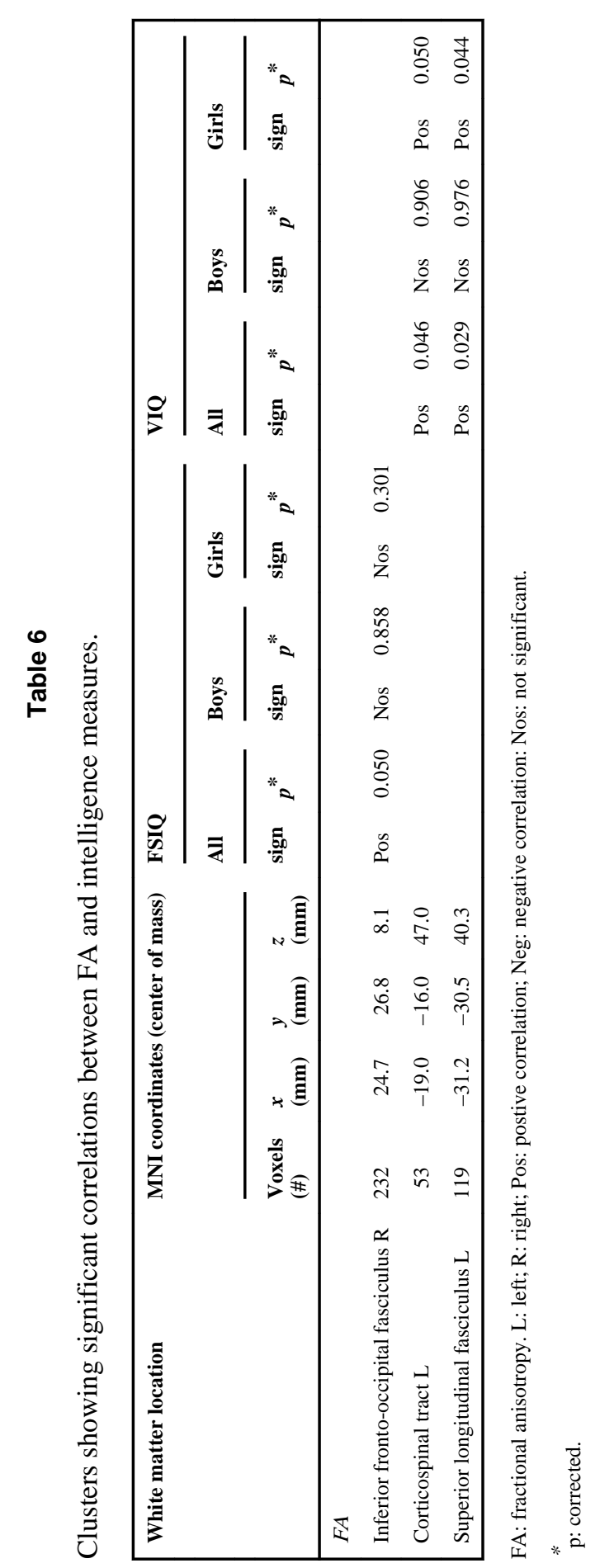

